\title{
Morphology of pig uterine subepithelial capillaries after topical and systemic oestrogen treatment
}

\author{
J. L. Keys and G. J. King* \\ Department of Animal and Poultry Science, The University of Guelph. Guelph, Ontario, \\ Canada N1G 2W1
}

\begin{abstract}
The ultrastructure of subepithelial capillaries in pig endometrium was studied after intrauterine and systemic oestradiol treatment. Gilts were killed on day 13 or 19 ( $n=4$ per day per treatment) after surgical introduction of Silastic beads containing either oestradiol or cholesterol into the uterine lumina on day 10 after oestrus. An additional group of gilts was injected i.m. with $5 \mathrm{mg}$ oestradiol valerate on days 11-15 of the oestrous cycle and killed on day 13 or day 19 ( $n=4$ per day). Light and electron microscope studies of endometrial samples revealed that cholesterol beads did not appear to affect subepithelial capillary structure. Both intrauterine and systemic treatment of gilts with oestradiol were associated with regional modification of the capillary wall involving attenuation and fenestration of the face directly underlying the uterine epithelium, accumulation of caveolae in the opposite face of the capillary, and the occurrence of discontinuous, multilayered capillary basal laminae. The similarity of these structural changes to those observed in capillaries at the time of embryonic attachment suggests that oestrogens of blastocyst origin may function to modify capillary morphology and possibly facilitate increased transcapillary traffic during the establishment of pregnancy.
\end{abstract}

\section{Introduction}

The uteri of a variety of mammals respond to the presence of preimplantation blastocysts by exhibiting increased uterine vascular permeability. This phenomenon, which appears to be crucial to placental and embryonic development, is thought to be induced by vasoactive mediators (Psychoyos, 1973). The structural basis and possible mediators for the profound capillary permeability accompanying the invasive implantation process of rodents (see Psychoyos, 1973) and rabbits (Hoffman et al., 1990) have been well documented. However, the nature and extent of capillary modification during embryonic attachment in species exhibiting noninvasive epitheliochorial placentation remains to be fully elucidated. Previous study of subepithelial capillaries in the uteri of cyclic and pregnant gilts indicated that structural indices of permeability were associated with the development of a close association between the blastocyst and uterine mucosa (Keys et al., 1986; Keys and King, 1988). Apposition between the conceptus and luminal surface of the endometrium before attachment in pigs may facilitate paracrine interactions between the trophoblast and uterus that result in modification of the uterine microvasculature.

Pig blastocysts, which are capable of oestrogen synthesis as early as day 10 after conception, are the main source of these compounds in utero during early pregnancy (Perry et al., 1973;

*Correspondence.

Received 19 April 1995.
King and Ackerley, 1985). The extensive growth of pig conceptuses before implantation is accompanied by the secretion of large amounts of trophoblast-derived oestrogen into the uterine lumen, beginning on about day 11.5 (Perry et al., 1973, 1976; Geisert et al., 1982a). Interaction between the conceptus and maternal epithelium in pigs is coincident with localized modification in endometrial structure (Keys and King, 1990), many features of which can be simulated by systemic or intrauterine application of oestradiol (Keys and King, 1992). Given the temporal relationship between the onset of oestrogen production by pig conceptuses and the structural evidence of increased uterine vascular permeability (Keys and King, 1988), the objective of this study was to investigate whether the ultrastructure of pig uterine subepithelial capillaries is influenced by application of exogenous oestradiol.

\section{Materials and Methods}

\section{Animals}

Twenty-four nulliparous crossbred gilts (Yorkshire $\times$ Landrace) of similar ages (about 225 days old) and $90-110 \mathrm{~kg}$ body mass were housed in groups of $6-8$ per pen $(3 \times 3.7 \mathrm{~m})$ and fed about $2.5 \mathrm{~kg}$ per day per animal of a corn-soybean diet. Water was available ad libitum from drinking nipples. Gilts were observed daily for oestrus in the presence of a vasectomized boar, and the first day of standing oestrus was designated as day 0 . After exhibiting two oestrous cycles of 
normal duration (18-22 days), each animal was assigned randomly to a treatment group and slaughter date. One group of eight gilts received an i.m. injection of $5 \mathrm{mg}$ oestradiol valerate (Squibb Pharmaceutical, Montreal) in $0.5 \mathrm{ml}$ sesame oil once a day at 16:00 $\mathrm{h}$ on days 11-15 of the oestrous cycle. Sixteen additional gilts were laparotomized on day 10 after oestrus. Anaesthesia was induced with Brietal Sodium (Eli Lilly, Toronto) at a dose of $1 \mathrm{mg} \mathrm{kg}{ }^{-1}$ i.v. and maintained with halothane (Somnothane, Hoechst, Montreal). Eight animals received oestradiol-impregnated Silastic beads and the rest received cholesterol-containing beads within their uterine lumina. Four beads were introduced into the lumen of each horn at each of the uterotubal junctions and mid-point through small puncture incisions. Each puncture was closed with a single suture to prevent herniation of the endometrium and escape of the beads. Details of the preparation and oestradiol release rates of the oestradiol-and cholesterol-containing beads were published by Keys and King (1992). Animals subjected to laparotomy were housed individually in gestation crates from the time of recovery from anaesthetic until slaughter. Four animals from each of the three treatment groups were killed by exsanguination on days 13 and 19.

\section{Tissue preparation for electron microscopy}

Immediately after slaughter, the right uterine horn was placed on ice, trimmed, and opened along its antimesometrial aspect; two $20 \mathrm{~cm}$ strips of tissue were pinned endometrial side up in a tray containing 0.2 mol cacodylate buffer $1^{-1}$ ( $\mathrm{pH}$ 7.4). Tissue with beads in situ could not be properly infiltrated and sectioned. The endometrial folds surrounding oestradiolimpregnated beads were gently separated and the beads removed. Cholesterol beads, which did not become engulfed by endometrial folds, were simply lifted off the endometrium. Flagpins were inserted lateral to the mesometrial region to mark bead sites; the tray was drained and flooded with $0.2 \mathrm{~mol}$ cacodylate buffer $\mathrm{l}^{-1}$ containing $3 \%$ glutaraldehyde $(\mathrm{w} / \mathrm{v}$; pH 7.4), and the tissue was left to harden. Multiple tissue samples directly associated with a bead, immediately adjacent to a bead, and distal to bead locations were processed from each animal. Six areas were selected randomly at the mesometrial region of two endometrial strips from each gilt injected with oestradiol valerate.

Endometrial samples were processed for light and electron microscopy using methods described by Keys and King (1989) and embedded in methacrylate and epon, respectively. Thick sections $(I \mu \mathrm{m})$ were cut from epon blocks at each of six sites per animal, treated with Paragon multiple stain (King et al., 1979) and screened for cross-sectional profiles of uterine epithelium. Ultrastructural observations were limited to capillaries and the terminal ends of arterioles and venules that were positioned immediately subjacent to the luminal epithelium. These vessels, which lack a muscular coat, are usually involved in phenomena of altered permeability (Cotran and Majno, 1964; Zweifach, 1973). Regions of the cross-sectional capillary wall were designated as proximal, distal and lateral relative to the uterine epithelium for comparison between sampling sites and treatment groups (Fig. 1).

\section{Results}

The cholesterol beads had migrated from the incision sites and were located randomly on the endometrial surface at day 13 . Most of the cholesterol beads were contained in the cervix or had passed out of the reproductive tract at day 19, and the ovaries contained avascular regressing corpora lutea and developing follicles. The thick firm mesometrium and loose oedematous endometrium of each uterus indicated prooestrous changes. Presumably luteolysis had occurred and animals were in the follicular phase of the subsequent cycle.

Beads containing oestradiol had also migrated from incision sites on day 13 and day 19 but were engulfed by fusion of vascular endometrial folds along the entire mesometrial aspect of the uterus. Vascularized corpora lutea and very small follicles characterized the ovaries of all animals in both oestradiol treatment groups at day 19 .

Plasma progesterone concentrations have been reported for these animals (Keys and King, 1992). Significant increases in plasma progesterone concentrations on day 19 in oestradiolinjected $\left(13.28 \pm 2.93 \mathrm{ng} \mathrm{ml}^{-1}\right)$ and oestradiol bead-treated $\left(9.39 \pm 1.72 \mathrm{ng} \mathrm{ml}^{-1}\right)$ groups $(P<0.05)$, relative to cholesterol bead-treated $\left(0.79 \pm 0.26 \mathrm{ng} \mathrm{ml}^{-1}\right)$ gilts, indicated that both routes of application of oestradiol had extended luteal life span beyond the normal time of luteolysis.

\section{Cholesterol bead treatment}

Consistent differences in the morphology of capillaries with respect to sampling site and day were not found in gilts in which cholesterol beads had been inserted. Nuclear position within the capillary wall was variable relative to the uterine epithelium and all aspects of the endothelial wall were usually of uniform thickness (Fig. 1). In less than $15 \%$ of capillaries, endothelial thickness was highly variable proximal to the uterine epithelium and attenuated segments were occasionally observed on days 13 and 19. A few fenestrations were observed in one animal on day 13, while a single fenestration was observed at one site in one gilt on day 19. When present, attenuated regions and fenestrations were restricted to the proximal endothelium, regardless of treatment group. Small vesicles were prominent at the luminal and external faces, and were scattered throughout the endothelium. Filopodia were pleomorphic and ranged in number from few to innumerable. Numerous dense inclusions and vacuoles of variable dimension were scattered throughout the cytoplasm. Endoplasmic reticulum and mitochondria were abundant near the nucleus at day 13 but were less prominent at day 19. Junctional complexes were long, tortuous and terminated in zonula occludente on the luminal side of the capillary. Intercellular gaps were not observed. The basal lamina was fuzzy, laminated and appeared to be discontinuous in many cases at day 13. This layer was intact at day 19, and in only one case did the basal lamina appear to comprise more than one layer.

\section{Oestradiol bead treatment}

Differences in capillary structure were not observed between sites at, adjacent to, or away from beads. In contrast to 


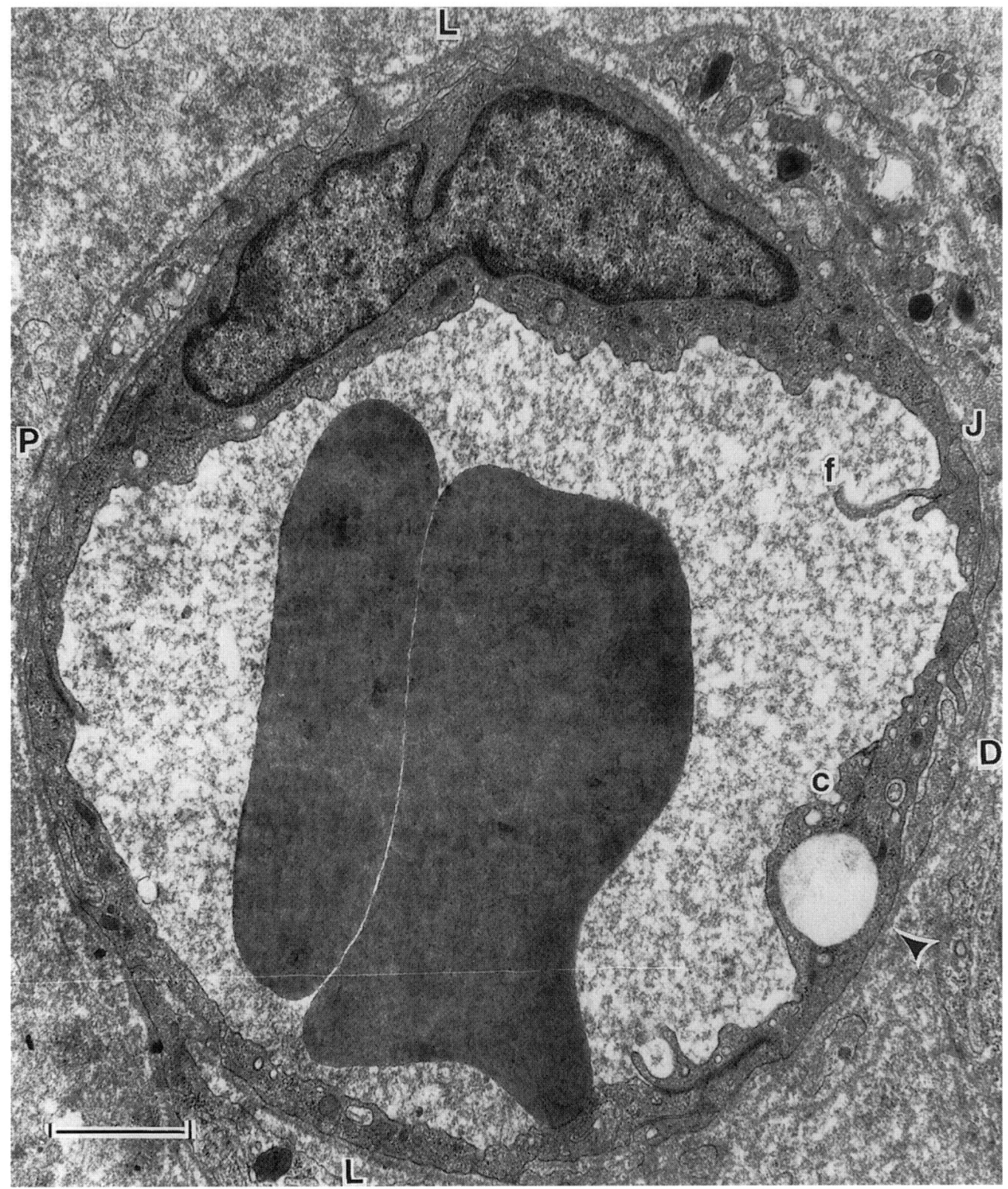

Fig. 1. Pig endometrium at day 13 of cholesterol bead treatment. The uterine epithelium lies beyond the left edge of the micrograph. The closest portion of the capillary wall to the uterine epithelium is designated as the proximal face ( $P$ ); the distal face (D) is the furthest away; the lateral faces (L) connect these to complete the capillary wall. The capillary wall lacks morphological evidence of regional modification. Caveolae (c) and vesicles are abundant at the luminal aspect. A few filopodia $(f)$ are evident. Polyribosomes and endoplasmic reticulum are scattered throughout the endothelial wall. The basal lamina is diffuse (arrowhead), and a zonula occludens occurs at the luminal extremity of an interendothelial junction (J). Scale bar represents $1 \mu \mathrm{m}$.

cholesterol bead-treated animals, marked regional modification of the capillary wall was observed at day 13 in oestradiol bead-treated animals (Fig. 2). Nuclei were predominantly located lateral or distal to the uterine epithelium and were associated with thick areas of cytoplasm containing numerous mitochondria, polyribosomes, plentiful endoplasmic reticulum and large vacuoles. Many small vesicles were primarily disposed at the luminal and external aspects of the endothelium. Dense inclusions were scattered throughout. Filopodia, which occurred on the lateral and distal faces and sometimes formed a complex network, varied in number and form, as observed in the cholesterol group.
The endothelium underlying the uterine cpithelium varied in thickness but generally formed long sinuous regions, several of which were studded with fenestrations (Fig. 3). Although a few dense inclusions were sometimes observed along the proximal endothelial face, this arca was otherwise featureless internally. Vesicles and filopodia were very rare. The appearance of the basal lamina was variable, appearing as an intact single or multilayered form, discontinuous and multilayered, or was absent from other capillaries. Endothelial junctions were not altered.

In contrast to the extensive regional modification of the capillary wall at day 13, animals containing oestradiol beads 


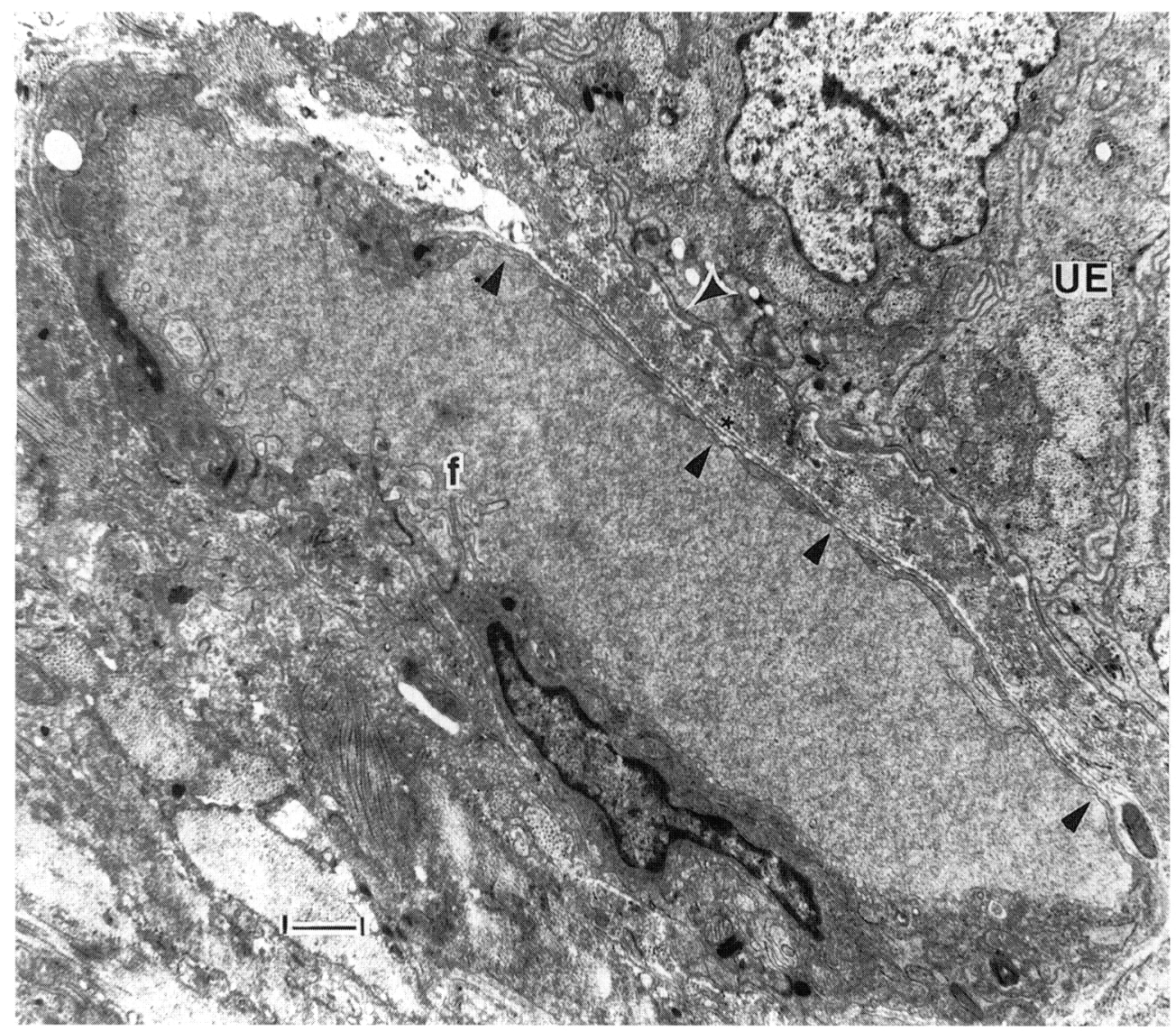

Fig. 2. Pig endometrium at day 13 of oestradiol bead treatment. Marked regional modification characterizes the capillary wall. The proximal face exhibits attenuation with several fenestrated areas (small arrowheads), and the long axis of the capillary is parallel to the uterine epithelium (UE). The distal face is thicker and contains an abundance of organelles, vesicles and complex filopodia $(\boldsymbol{f})$. The basal lamina below the uterine epithelium appears distinct and intact (large arrowhead), while that of the capillary is discontinuous and consists of several thin layers $\left({ }^{*}\right)$. Scale bar represents $I \mu \mathrm{m}$.

in utero at day 19 had subepithelial capillaries that lacked evidence of regionalization and were characterized by a paucity of organelles indicative of metabolic activity (Fig. 4). Nuclear position varied, as did endothelial thickness. Thinning proximal to the luminal epithelium was restricted to one short attenuated segment that lacked fenestrations. The inner surface was irregular with a few small filopodia. The basal lamina was discontinuous, sometimes thick and diffuse in appearance, and often composed of several layers.

\section{Oestradiol iniection}

Modifications of capillary structure which were similar to those at day 13 of oestradiol bead treatment were also observed in gilts at day 13 of oestradiol injection. The endothelium of the proximal face, which was consistently very close to and followed the convolutions of the uterine epithelium and associated basal lamina (Fig. 5), usually contained fenestrated segments. The wall was consistently thicker lateral and distal to these regions and contained a large number of dense inclusions, small vesicles and plentiful endoplasmic reticulum and mitochondria (Fig. 6). Filopodia were either

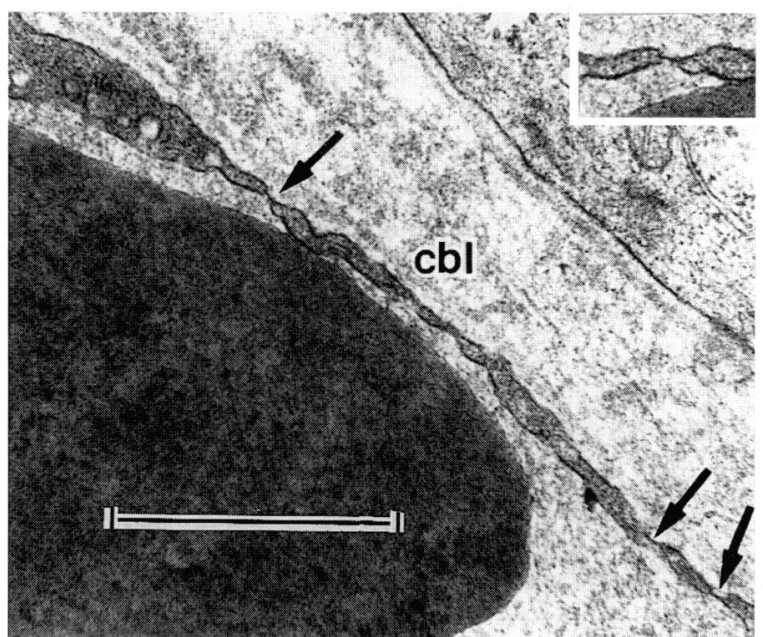

Fig. 3. Pig endometrium at day 13 of oestradiol bead treatment. The uterine luminal epithelium is evident in the upper right corner. The attenuated proximal face contains three discrete fenestrations closed by diaphragms (arrows). The capillary basal lamina (cbl) is diffuse and discontinuous. Scale bar represents $1 \mu \mathrm{m}$. Inset: Higher magnification of left fenestration. 


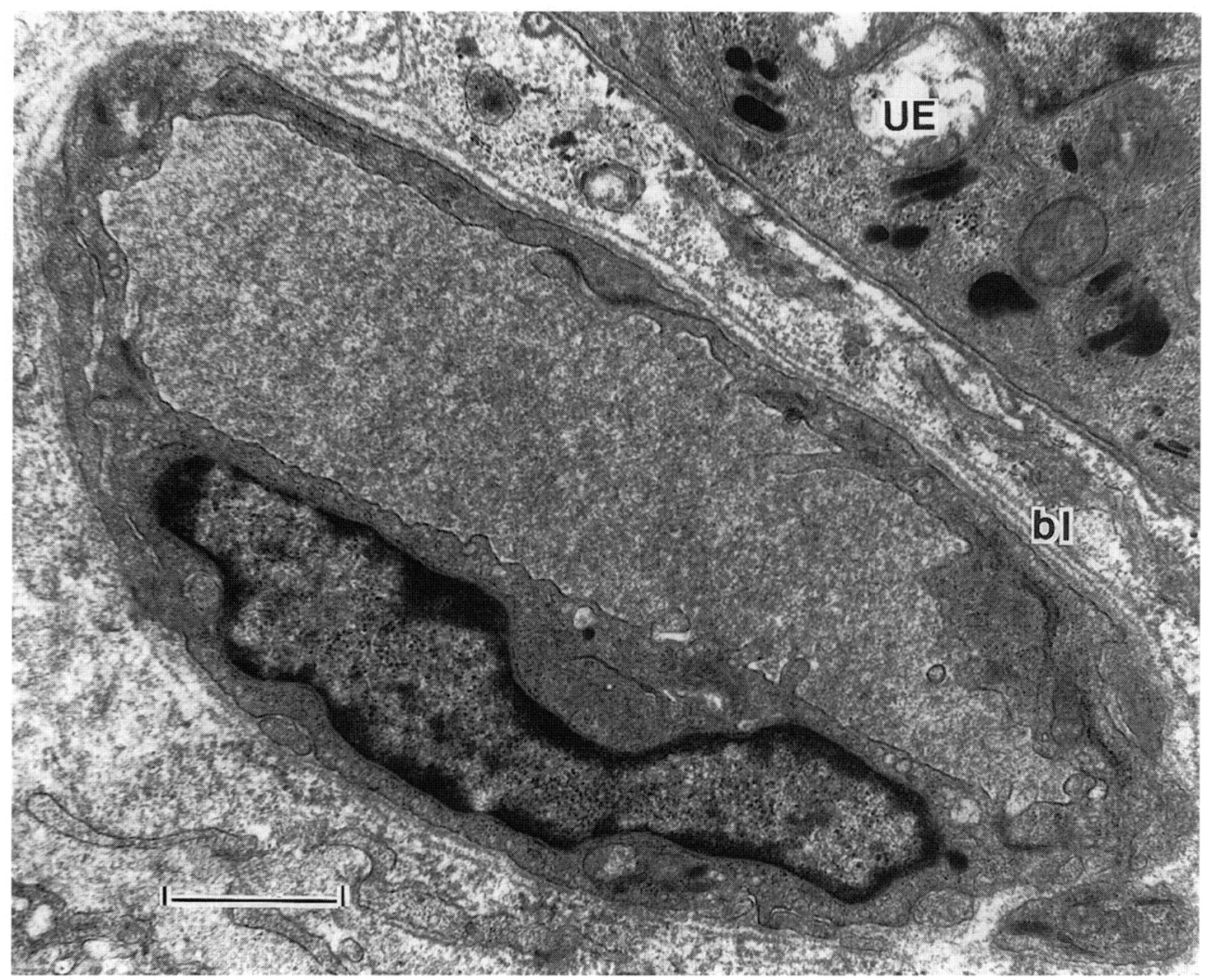

Fig. 4. Pig endometrium at day 19 of oestradiol bead treatment. The proximal face lacks attenuation. A paucity of organelles is evident except for small vesicles, which are particularly abundant at the luminal and external faces of the endothelium. The basal lamina (bl) remains multi-layered. UE: uterine epithelium. Scale bar represents $1 \mu \mathrm{m}$.

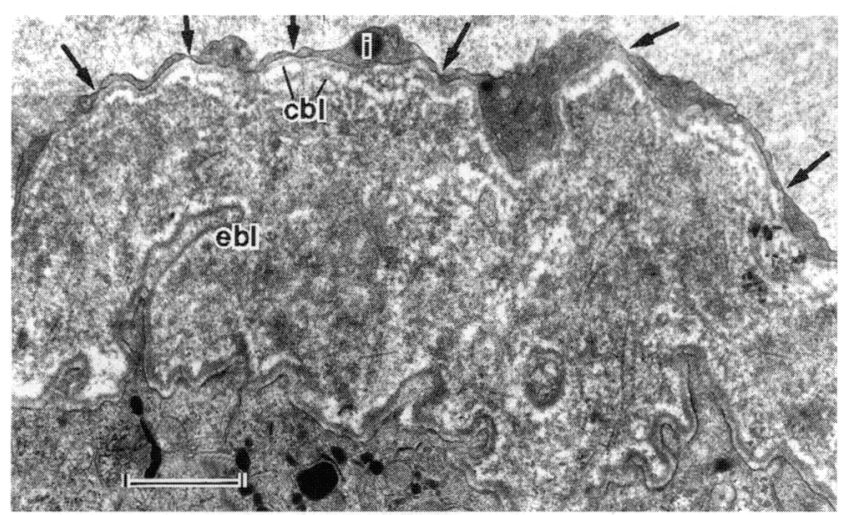

Fig. 5. Pig endometrium at day 13 of oestradiol injection. Structural features of the extensively attenuated area of proximal endothelium are limited to multiple fenestrations (arrows), a few vesicles and dense inclusions (j). The capillary basal laminae (cbl) are diffuse and discontinuous, while the basal lamina associated with the uterine epithelium (ebl) is thick and separated from the basal epithelial plasmalemma in some areas. Scale bar represents $1 \mu \mathrm{m}$.

absent or present as a few blunt forms. Junctional complexes were extensive. The appearance of the basal lamina was highly variable, as described for intraluminal oestradiol treatment.

Attenuated endothelium, usually containing fenestrated regions, occurred commonly subjacent to the epithelium at day
19 in the oestradiol injection group. The capillaries were generally oriented with their long axis parallel to the uterine epithelium, presenting a broad face of endothelium adjacent to this tissue (Fig. 7). Irregular wall thickness or uniform thickness with organelles dispersed throughout characterized other nonfenestrated capillaries. Abundant small vesicles were primarily disposed near the lumen. Numerous dense inclusions, mitochondria and endoplasmic reticulum were found on the distal face. The occurrence of filopodia on the distal face ranged from a few to an extensive network, but these extensions were rare along the proximal face. The basal lamina remained discontinuous.

\section{Discussion}

Incubation of beads in vitro (Keys and King, 1992) indicated that the pattern of steroid release differed from that of developing conceptuses (Robertson ef al, 1978; Bazer of al, 1982; Stone and Seamark, 1985). Although the large surge of oestradiol released from the beads on days 11 and 12 simulated production of this steroid by pig conceptuses, the subsequent release of much smaller daily amounts indicated that the beads failed to mimic the second period of increased release from conceptuses starting on day 15 of pregnancy. In addition to an initial oestrogen stimulation on day 11 , a secondary prolonged exposure to increased oestrogen beginning on day 14 is required to completely induce pseudopregnancy (Geisert et al., 


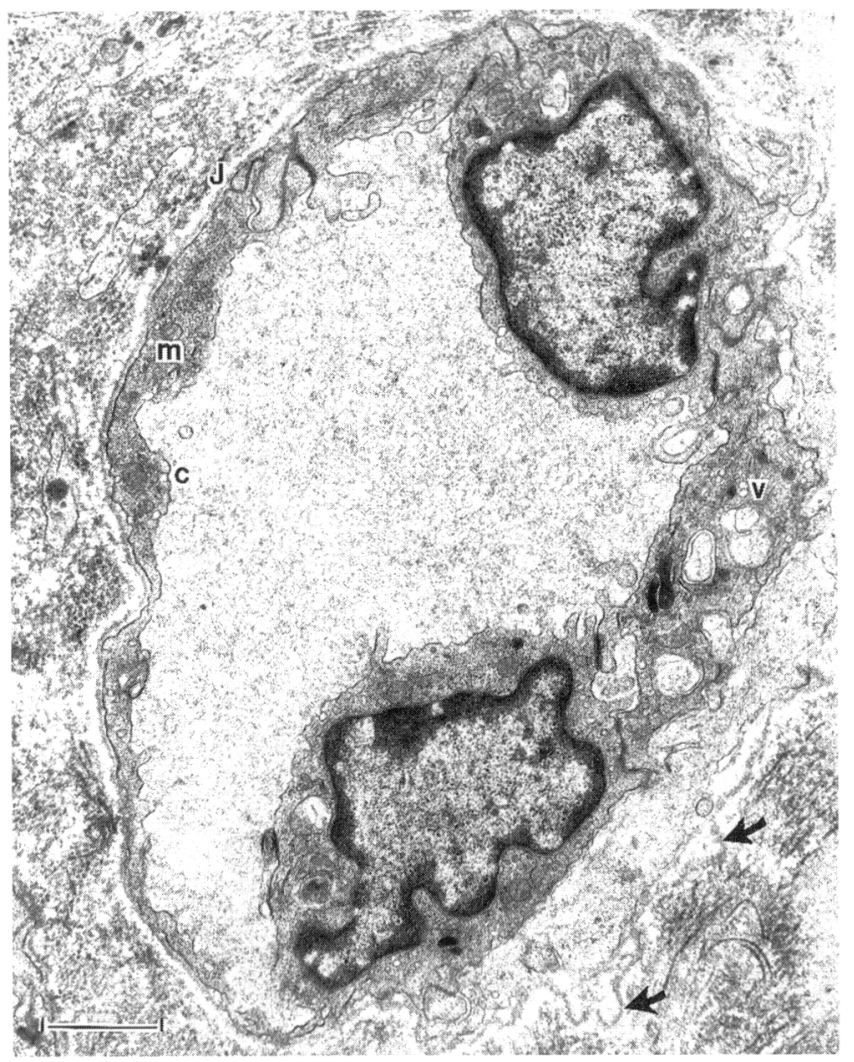

Fig. 6. Pig endometrium at day 13 of oestradiol injection. The epithelial-stromal interface lies to the left of the image. This capillary lacks fenestrated regions and contains polyribosomes, endoplasmic reticulum, mitochondria $(\mathrm{m})$, intracellular vesicles (v), and caveolae (c) which are dispersed throughout the wall. Junctions (J) remain tortuous and are sealed by a dense appearing zonula occludens. The basal lamina is diffuse, incomplete and folded in some areas (arrows). Scale bar represents $1 \mu \mathrm{m}$.

1987). Therefore, although the beads released sufficient oestrogen to stimulate endometrial changes and prolong luteal function until day 19, concomitant modifications in capillary structure must be interpreted with caution since the beads produced what may be considered pharmacological rather than physiological doses during the initial stages, and yet the amounts released after the initial peak may not have been sufficient to extend luteal function beyond 28 days (King and Rajamahendran, 1988).

Animals that received cholesterol beads had subepithelial capillaries that were not structurally different from the corresponding days of the cycle (Keys and King, 1988). In contrast, the subepithelial capiliaries of animals that had received oestradiol beads exhibited morphology similar to that at days 13 and 19 of pregnancy (Keys and King, 1988), indicating that modifications were due to the steroid the beads contained, rather than their physical presence. These alterations included marked regional modification of the capillary wall, with attenuated, fenestrated endothelium forming the proximal face, plentiful vesicles and filopodia on the thicker distal face, as well as a discontinuous and sometimes multilayered basal lamina. In contrast to animals at day 19 of pregnancy (Keys and King, 1988), structural indications of increased permeability were

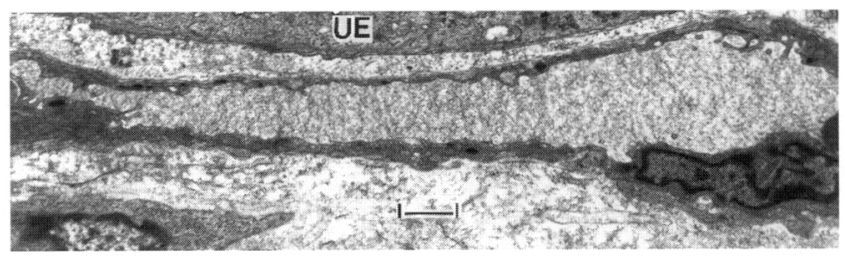

Fig. 7. Pig endometrium at day 19 of oestradiol injection. Uterine epithelium (UE) occupies the upper portion of the micrograph. This overview indicates parallel orientation of the long axis of the capillary to the uterine epithelium, with a long attenuated proximal endothelial face in extensive close proximity to the uterine epithelium. Scale bar represents $I \mu \mathrm{m}$.

lacking at day 19 of oestradiol bead treatment, although the basal lamina remained discontinuous, thick, and multilayered. The amount of steroid released from the beads into the uterine lumen at this stage (Keys and King, 1992) was probably inadequate to maintain the alterations. In contrast, capillary modifications similar to those observed in pregnant gilts and in oestradiol bead treated gilts on day 13 persisted until day 19 in the oestradiol-injected group. Differences in the time course of the vascular changes between intraluminal and systemic application of oestrogen may be explained by a more stable amount of oestrogen entering the uterus during the latter treatment. A positive correlation between concentrations of this steroid and the number of uterine intra-endothelial vesicles, vesicle fusions and fenestrations has been observed in other species (Wolff and Merker, 1966; Friederici, 1967; Martin et al., 1973). Oestradiol may act directly in structural modification of the endothelium through interaction with the endothelial oestradiol receptor (Colburn and Buonassisi, 1978), or by inducing synthesis of vasoactive substances such as histamine and prostaglandin.

Morphological signs of general metabolic activation of the endothelium at day 13 of oestradiol bead treatment and days 13 and 19 of oestradiol injection included extensive granular endoplasmic reticulum, numerous mitochondria, and an abundance of vesicles and caveolae. Metabolically activated endothelium has been described at implantation sites in many species (Enders and Schlafke, 1979) and the ultrastructural similarity to capillaries exposed to angiogenic stimuli (Christofferson and Nilsson, 1988) indicates that these features reflect angiogenesis.

Regional modifications in capillary morphology after oestradiol treatment suggest an increase in transcapillary traffic by transport of material across the endothelium via fenestrae at the attenuated proximal face and exchange by vesicular transport at the thicker distal face. The incidence of caveolae and intraendothelial vesicles, which provide a vehicle for transport of large molecules such as ferritin (Bruns and Palade, 1968), horseradish peroxidase (Graham and Karnovsky, 1966) and dextrans (Simionescu et al., 1972), was markedly increased. Laforest and King (1992) demonstrated that ferritin injected directly into a uterine artery of one gilt on day 15 of pregnancy is transported across the capillary wall by endothelial vesicles and transendothelial channels. Fusion of vesicles with the endothelial surface is involved in the formation of fenestrations (Elfvin, 1965; Wolff and Merker, 1966; Palade and Bruns, 1968; Casley-Smith, 1970). Small numbers of vesicles in flattened 
areas near fenestrations or in non-fenestrated capillaries have been observed in many tissues; this suggests that vesicles are used during the process of elongation of vessels and enlargement of endothelial surfaces (Wolff, 1966; 1977).

Fenestrations are restricted in distribution to endothelia across which large amounts of solute or fluid must traverse (Yamada, 1955; Casley-Smith, 1971; Renkin, 1978; Buonassisi and Colburn, 1980) and are densely packed in fields of extensively flattened endothelium (Wolff, 1977), as was the case along the proximal face of subepithelial capillaries in the oestrogen-treated uteri examined, as well as in the uteri of pregnant pigs (Keys and King, 1988). Although these pores are generally closed by diaphragms (Maul, 1971), molecules as large as ferritin pass through (Casley-Smith, 1970). Increased numbers of fenestrated capillaries at implantation sites in rats suggest that fenestrae also contribute to the increased vascular permeability in this species (Abrahamsohn et al., 1983). Fenestrations proliferate under the influence of steroids (Wolff and Merker, 1966) and in response to unidentified factors seemingly produced by epithelial cells (Campbell and Uehara, 1972), which would explain their consistent presence along the capillary wall directly underlying the uterine epithelium. Functionally, extensive profiles of capillary wall parallel, and in close proximity, to the uterine epithelium would increase the area of the inner vessel surface for exchange, and attenuation of the capillary wall would decrease the interhaemal distance, both of which favour maternal-fetal exchange (Battaglia, 1981).

Differences in the tortuous nature of cell junctions or the presence of tight junctions were not observed at any of the stages or in any of the treatments examined. Fusion of the external leaflets of the plasmalemmae of endothelial cells at intercellular clefts (Simionescu et al., 1975) are a physical determinant of permeability. In species exhibiting more invasive forms of placentation, implantation is associated with marked increases in the number of interendothelial gaps and frank capillary leakage (Abrahamsohn et al., 1983; Hoffman and Hoos, 1984; Hoffman et al., 1990); both of these microcirculatory effects can be reproduced in immature rats by systemic injection of oestradiol (Ham et al., 1970). Differences between our observations in pigs and those reported for rodents indicate clear species differences in microvascular response to oestradiol as a participant in placental development.

The basal lamina, produced and organized by the endothelium and adhering cells (Pierce and Nakane, 1967; Kefalides and Denduchis, 1969; Bar and Wolff, 1972) disintegrates in response to vasoactive agents or degeneration (Cotran and Majno, 1964). If regeneration occurs within a reasonable time, a new basal lamina forms inside the old scaffold, resulting in a multi-layered structure. Multi-lamellar and thickened basal laminae characterize endothelial damage (Pierce and Nakane, 1969; Vracko and Benditt, 1972), as well as angiogenesis (Findlay, 1987). Degradation of the basal lamina of a microvessel is thought to reflect the action of collagenase and plasminogen activator secreted by the endothelial cells in response to an angiogenic stimulus (Findlay, 1987). The occurrence of discontinuous, diffuse, laminated basal laminae in oestrogen-treated and pregnant pigs (Keys and King, 1988) reflects a subepithelial vascular network which is being restructured and rapidly expanded. Given the complex nature of angiogenesis, involving cell division, chemotaxis and elaboration of basal lamina (Folkman, 1985), many factors including ovarian and conceptus steroids are probably involved. The basal lamina regulates the exit of material from uterine capillaries following oestradiol treatment, as illustrated using mercuric sulphide (Friederici, 1967) and carbon (Ham et al., 1970).

The increased incidence of fenestrations and endothelial vesicles following oestrogen administration is probably related to increased transcapillary transport rather than to a marked increase in capillary permeability. Ultrastructural features of the subepithelial capillaries in oestrogen-treated gilts were also consistent with angiogenic activity. These changes mimic those observed in the microvasculature of pregnant uteri, in temporal association with apposition between the elongated blastocyst and endometrium, and elaboration of oestrogen by the conceptus. They also coincide with two previously documented uterine responses to intraluminal or systemic oestrogens: increased blood flow to the gravid uterine horns and histotroph production (Ford and Christenson, 1979; Ford, 1985; Geisert et al., 1982a, b). On the basis of the amount of aromatase activity (Flint et al, 1979), tissue concentrations of oestrogens (Gadsby and Heap, 1978) and increased oestrogen concentrations in the uterine flushings of pregnant pigs (Zavy et al., 1980; Ford et al., 1982), it is evident that the blastocysts are the main source of oestrogen in utero during this period. These facts indicate that the conceptus can orchestrate the expansion and modification of the maternal vasculature necessary to ensure placentation. Concomitant increases in transcapillary traffic, uterine blood flow and histograph production, as well as attenuation of the subepithelial capillary wall, undoubtedly facilitate the passage of nutrients toward the rapidly developing conceptus and the transfer of blastocyst-induced products into maternal circulation. Disturbances in the exchange of materials across the uterine subepithelial capillaries during this period of rapid embryonic growth may be a factor contributing to the high early embryonic mortality associated with this phase.

The authors thank B. Atkinson, A. Attefuah, D. Bellissimo and D. Wey for technical assistance and Masterworks Video Productions for provision of darkroom facilities. Research funds were provided by the Natural Science and Engineering Research Council and the Ontario Ministry of Agriculture and Food.

\section{References}

Abrahamsohn $P$, Lundkvist $O$ and Nilsson $O$ (1983) Ultrastructure of the endometrial blood vessels during implantation of the rat blastocyst Cell and Tissue Research $229269-280$

Bar T and Wolff JR (1972) The formation of capillary basement membranes during internal vascularization of the rat's cerebral cortex Zeitschrift Fuer Mikroskopisch-Anatomische Forschung (Leipzig) $133231-248$.

Battaglia FC (1981) Placental transfer in relation to fetal demand Placenta (Supplement 1) 3-9

Bazer FW, Geisert RD, Thatcher WW and Roberts RM (1982) The establishment and maintenance of pregnancy In Control of Pig Reproduction pp 227-252 Eds DJA Cole and GR Foxcroft. Butterworth Scientific, London

Bruns RR and Palade GE (1968) Studies on blood capillaries: Il. The transport of ferritin molecules across the wall of muscle capillaries Journal of Cell Biology $37277-299$

Buonassisi V and Colburn P (1980) Hormone and surface receptors in vascular endothelium Advances in Microcirculation 9 76-94

Campbell GR and Uehara Y (1972) Formation of fenestrated capillaries in mammalian vas deferens and ureter transplants Zeitschrift Fuer MikroskopischAnatomische Forschung (Leipzig) 134 167-173 
Casley-Smith JR (1970) The functioning of endothelial fenestrae on the arterial and venous limbs of capillaries, as indicated by the differing directions of passage of proteins Experientia 22 852-853

Casley-Smith JR (1971) Endothelial fenestrae in intestinal villi. Differences between the arterial and venous ends of the capillaries Microvascular Research $15 \quad 123-135$

Christofferson RH and Nilsson BO (1988) Morphology of the endometrial microvasculature during early placentation in the rat Cell and Tissue Research $253209-220$

Colburn P and Buonassisi V (1978) Estrogen-binding sites in endothelial cell cultures Science $201817-819$

Cotran RS and Majno G (1964) A light and electron microscopic analysis of vascular injury Annals of the New York Academy of Science 116 750-764

Elfvin LG (1965) The ultrastructure of the capillary fenestrae in the adrenal medulla of the rat Journal of Ultrastructural Research 12 687-704

Enders AC and Schlafke S (1979) Comparative aspects of blastocystendometrial interactions at implantation In Maternal Recognition of Pregnancy pp 3-32 Ed. J Whelan. Ciba Foundation Symposium 64, Excerpta Medica, Amsterdam, Oxford, New York

Findlay JK (1987) Angiogenesis in reproductive tissues Journal of Endocrinology $111357-366$

Flint APF, Burton RD, Gadsby JE, Saunders PTK and Heap RB (1979) Blastocyst oestrogen synthesis and the maternal recognition of pregnancy in Maternal Recognition of Pregnancy pp 209-238 Ed. J. Whelan. Ciba. Foundation Symposium 64, Excerpta Medica, Amsterdam, Oxford, New York

Folkman J (1985) Tumor angiogenesis Advances in Cancer Research 43 175-203

Ford SP (1985) Maternal recognition of pregnancy in the ewe, cow and sow: vascular and immunological aspects Theriogenology 23 145-159

Ford SP and Christenson RK (1979) Blood flow to uteri of sows during the estrous cycle and early pregnancy: local effect of the conceptus on the uterine blood supply Biology of Reproduction 21 617-624

Ford SP, Christenson RK and Ford JJ (1982) Uterine blood flow and uterine arterial, venous and luminal concentrations of oestrogens on days 11, 13 and 15 or after oestrus in pregnant and non-pregnant sows Journal of Reproduction and Fertility 64 185-190

Friederici HHR (1967) The early response of uterine capillaries to estrogen stimulation Laboratory Investigation 17 322-333

Gadsby JE and Heap RB (1978) Steroid hormones and their synthesis in the early embryo In Novel Aspects of Reproductive Biology pp 263-283 Eds CH Spilman and JW Wilks. Spectrum Publications, New York

Geisert RD, Renegar HR, Thatcher WW, Roberts RM and Bazer FW (1982a) Establishment of pregnancy in the pig. I. Interrelationships between preimplantation development of the pig blastocyst and uterine endometrial secretions Biology of Reproduction 27 925-939

Geisert RD, Thatcher WW, Roberts RM and Bazer FW (1982b) Establishment of pregnancy in the pig. III. Endometrial secretory response to estradiol valerate administered on day 11 of the estrous cycle Biology of Reproduction 27 957-965

Geisert RD, Zavy MT, Wettemann RP and Biggers BG (1987) Length of pseudopregnancy and pattern of uterine protein release as influenced by time and duration of oestrogen administration in the pig Journal of Reproduction and Fertility 79 163-172

Graham RC and Karnovsky MJ (1966) Glomerular permeability: ultrastructural cytochemical studies using peroxidases as protein tracers journal of Experimental Medicine 124 1123-1134

Ham KN, Jurley JV, Lopata A and Ryan GB (1970) A combined isotopic and electron microscopic study of the response of the rat uterus to exogenous oestradiol Journal of Endocrinology 46 71-81

Hoffman LH and Hoos PC (1984) Morphology of vascular leakage at rabbit implantation sites Anatomical Record (Abstracts) 208 75a

Hoffman LH, Winfrey VP and Hoos PC (1990) Sites of endometrial vascular leakage during implantation in the rabbit Anatomical Record $22747-61$

Kefalides NA and Denduchis B (1969) Structural components of epithelial and endothelial basement membranes Biochemistry 8 4613-4621

Keys JL and King GJ (1988) Morphological evidence for increased uterine vascular permeability at the time of embryonic attachment in the pig Biology of Reproduction 39 473-487

Keys JL and King GJ (1989) Structural changes in the luminal epithelium of the porcine uterus between Days 10 and 19 of the estrous cycle American Journal of Anatomy $18542-57$

Keys JL and King GJ (1990) Microscopic examination of porcine conceptusmaternal interface between Days 10 and 19 of pregnancy American Journal of Anatomy 188 221-238
Keys JL and King GJ (1992) Effects of topical and systemic estrogen on morphology of porcine uterine luminal epithelia Biology of Reproduction 46 1165-1175

Keys JL, King GJ and Kennedy TG (1986) Increased uterine vascular permeability at the time of embryonic attachment in the pig Biology of Reproduction 34 405-411

King G) and Ackerley CA (1985) Demonstration of oestrogens in developing pig trophectoderm and yolk sac endoderm between days 10 and 16 Journal of Reproduction and Fertility 73 361-367

King GJ and Rajamahendran R (1988) Comparison of plasma progesterone profiles in cyclic, pregnant, pseudopregnant and hysterectomized pigs between 8 and 27 days after oestrus Journal of Endocrinology 119 111-116

King GJ, Atkinson BA and Robertson HA (1979) Development of the bovine placentome during the second month of gestation Journal of Reproduction and Feritity 55 173-180

Laforest JP and King GJ (1992) Structural and functional aspects of porcine endometrial capillaries on Days 13 and 15 after oestrus or mating Journal of Reproduction and Fertility 94 269-277

Martin L, Finn CA and Trinder G (1973) Hypertrophy and hyperplasia in the mouse uterus after oestrogen treatment: an autoradiographic study Joumal of Endocrinology 56 133-144

Maul GG (1971) Structure and formation of pores in fenestrated capillaries Journal of Ultrastructural Research $36768-782$

Palade GE and Bruns RR (1968) Structural modulations of plasmalemmal vesicles Journal of Cell Biology 37 633-649

Perry IS, Heap RB and Amoroso EC (1973) Steroid hormone production by pig blastocysts Nature $\mathbf{2 4 5} 45-47$

Perry JS, Heap RB, Burton RD and Gadsby JE (1976) Endocrinology of the blastocyst and its role in the establishment of pregnancy Journal of Reproduction and Fertility Supplement 25 85-104

Pierce GB and Nakane PK (1967) Antigens of epithelial basement membranes of mouse, rat and man. A study utilizing enzyme-labelled antibody Laboratory Investigation 17 499-514

Pierce GB and Nakane PK (1969) Basement membranes: 'synthesis and deposition in response to cellular injury Laboratory Investigation 21 27-41

Psychoyos A (1973) Endocrine control of egg implantation In Handbook of Physiology pp 187-215 Eds RO Greep, EB Astwood and SR Geiger. American Physiological Society, Bethesda

Renkin EM (1978) Transport pathways through capillary endothelium Microvascular Research 15 123-135

Robertson HA, King GJ and Dyck GW (1978) The appearance of oestrone sulphate in the peripheral plasma of the pig early in pregnancy Journal of Reproduction and Fertility 52 337-338

Simionescu M, Simionescu N and Palade GE (1975) Segmental differentiations of cell junctions in the vascular endothelium. The microvasculature journal of Cell Biology $67863-885$

Simionescu N, Simionescu M and Palade GE (1972) Permeability of intestinal capillaries. Pathway followed by dextrans and glycogen Journal of Cell Biology 53 365-392

Stone BA and Seamark RF (1985) Steroid hormones in washings and in plasma of gilts between Days 9 and 15 after oestrus and between Days 9 and 15 after coitus Journal of Reproduction and Fertility 75 209-22I

Vracko R and Benditt EP (1972) Basal lamina: the scaffold for orderly cell replacement Journal of Cell Biology 55 406-419

Wolff J (1966) Elektonenmikroskopische untersuchungen uber die vesikulation im kapillarendothel Zeitschrift Fuer Mikroskopisch-Anatomische Forschung (Leipzig) 73 143-164

Wolff J (1977) Ultrastructure of the terminal vascular bed as related to function. In Microcirculation Vol. I pp 95-130. University Park Press, Baltimore

Wolff J and Merker H-J (1966) Ultrastruktur und bildung von popren im endothel von porosen und geschlossenen kapillaren Zeitschrift Fuer Mikroskopisch-Anatomische Forschung (Leipzig) 73 174-191

Yamada E (1955) The fine structure of the renal glomerulus of the mouse Journal of Biophysical and Biochemical Cytology 1 55I-556

Zavy MT, Bazer FW, Thatcher WW and Wilcox CJ (1980) A study of prostaglandin $F_{2 u}$ as the luteolysin in swine. V. Comparison of prostaglandin $F$, progestins, estrone and estradiol in uterine flushings from pregnant and nonpregnant gilts Prostaglandins $20837-851$

Zweifach BW (1973) Microvascular aspects of tissue injury. In The Inflammatory Process (2nd Edn) pp 3-46 Eds BW Zweifach, L Grant and RT McCluskey. Academic Press, New York 